
Ава клинических случая

\author{
Д. Помарино
}

Дж. Р. Трен

А. А. Емелина ${ }^{1}$, кандидат медицинских наук

Praxis Pomarino, Гамбург, Германия

Резюме. В данной статье приводится описание двух клинических случаев пациенток с ходьбой на носках. В рамках диагностики обеим пациенткам был проведен генетический тест на наследственную сенсомоторную нейропатию, который выявил у одной пациентки мутацию в гене $N D R G 1$ с редким вариантом c.1022G $>$ A; p.arg341His (частота минорного аллеля $<0,01 \%$ ), у другой пациентки обнаружен гетерогенный вариант c.1053_1082del и NM_001135242.1 p.Thr360_Gly369del. Данные мутации ассоциированы с болезнью Шарко-Мари-Тута (тип 4D), но ни у одной из пациенток клинически не было обнаружено данной наследственной нейропатии, в то же время диагноз идиопатической ходьбы на носках также сомнителен, поскольку в обоих случаях потребовалось достаточно серьезное лечение. Поэтому разумно предположить, что обе пациентки ходят на цыпочках по генетической причине. Ключевые слова: идиопатическая ходьба на носках, болезнь Шарко-Мари-Тута, мутация, ген NDRG1.

Для цитирования: Помарино Д., Трен Дж. Р., Емелина А. А. Идиопатическая ходьба на носках и гетерозиготная мутация в гене NDGR1: два клинических случая // Лечащий Врач. 2021; 6 (24): 7-8. DOI: 10.51793/OS.2021.24.6.001

\title{
Idiopathic toe walking and heterozygous mutation in the NDGR1 gene: 2 clinical cases
}

D. Pomarino, J. R. Tren, A. A. Emelina ${ }^{1}$

Praxis Pomarino, Hamburg, Germany

Abstract. This article describes two clinical cases of patients with tiptoe walking. As part of the diagnosis, both patients underwent a genetic test for hereditary sensorimotor neuropathy, which revealed in one patient a mutation in the $N D R G 1$ gene with a rare variant $c .1022 G>A$; p.arg341his (minor allele frequency $<0.01 \%$ ), in the other patient a heterogeneous variant c.1053_1082del and NM_001135242.1 p.thr360_ gly369del was detected. These mutations are associated with Charcot-Marie-Toute disease (type 4D), but none of the patients were clinically diagnosed with this hereditary neuropathy, while the diagnosis of idiopathic toe-walking is also doubtful, since in both cases quite serious treatment was required. Therefore, it is reasonable to assume that both patients walk on tiptoe for a genetic reason.

Keywords: idiopathic toe walking, Charcot-Marie-Toute disease, mutation, NDRG1 gene.

For citation: Pomarino D., Tren J. R., Emelina A. A. Idiopathic toe walking and heterozygous mutation in the NDGR1 gene: 2 clinical cases // Lechaschy Vrach. 2021; 6 (24): 7-8. DOI: 10.51793/OS.2021.24.6.001

$\mathrm{T}$ ермин «идиопатическая ходьба на носках» (ИХН) описывает патологическое нарушение походки, которое характеризуется тем, что пациент большую часть времени ходит на передней части стопы, не перекатываясь через пятку [1].

При дифференциальной диагностике для полноценной терапии данной аномалии должны быть исключены неврологические или ортопедические заболевания, которые также могут способствовать появлению ходьбы на носках. Если у пациента не удается определить клиническую причину ходьбы на носках, выставляется диагноз «идиопатическая ходьба на носках» [2]. Однако, на наш взгляд, данный термин может приводить к ложному убеждению, что ИХН не представляет собой медицинскую проблему и исчезает сама по себе. В то же время ранее нами при генетическом тестировании были выявлены причинные мутации аномалий походки без неврологических или ортопедических заболеваний [3].

${ }^{1}$ Контактная информация: info@ptz-pomarino.de
В данной работе приводится описание двух клинических случаев пациенток, не связанных между собой родством, у которых наблюдается выраженная ходьба на носках, требующая лечения, и мутации в гене $N D R G 1$. Соответствующие клинические детали и результаты генетического тестирования описаны ниже.

\section{Киинический случай № 1}

Для лечения ярко выраженной ходьбы на носках в праксис обратились родители пациентки А., 2 лет. Из анамнеза известно, что ребенок от второй беременности и вторых родов. Беременность и роды протекали без осложнений. На момент рождения вес -3200 г, рост - 51 см. Период новорожденности и младенческий возраст - без особенностей.

Пациентка начала уверенно ходить в 18 мес, демонстрируя с самого начала экстремальную ходьбу на носках, которая иногда переходила в ходьбу на кончиках пальцев. Аномальная походка наблюдалась в $100 \%$ от всего времени ходьбы. В остальном - анамнез без особенностей, рост и развитие 
соответствовали возрастным нормам. Родители пациентки не являются кровными родственниками.

При осмотре была обнаружена тяжелая форма двусторонней ходьбы на носках.

Клинико-неврологическое исследование выявило затрудненное движение на носках с обеих сторон при эквинусной стопе, отчетливо повышенный тонус икроножных мышц с обеих сторон и подвижность верхнего голеностопного сустава при оценке с помощью нейтрально-нулевого метода - 0-0-40 справа и $0-10-40^{\circ}$ слева при сгибании и разгибании колена. Походка была быстрой, при этом контакт пятки с полом отсутствовал, вместо этого девочка частично ходила на кончиках пальцев ног.

Верхние конечности - без отклонений. Позвоночник, тазобедренные и коленные суставы также в норме.

Ахиллово сухожилие укорочено с двух сторон, в области, расположенной над ахилловым сухожилием, отчетливо виден V-образный знак.

Мышечные рефлексы не изменены, симптом Бабинского отрицательный, рефлекторные зоны в норме. Генетический тест на возможную наследственную моторно-сенсорную нейропатию как причину ходьбы на носках выявил изменение гена $N D R G 1$ на гетерозиготный вариант с.1022G>A; p.arg.341 his. Частота минорного аллеля была сравнительно редкой и составляла $<0,01 \%$, мутация была описана с неясным значением для аномалии походки из-за низкого уровня распознавания. Вариант наследуется как аутосомно-рецессивный признак.

Лечение высокой дозой ботулотоксина (100 ед./каждая нога), пирамидными стельками и ночными шинами не дало результатов, улучшение не наступило.

В возрасте трех лет пациентка была госпитализирована для хирургического лечения ходьбы на носках. Проведена операция по методу Ульзибата, после чего на обе конечности наложен гипс. На данный момент, согласно плану, начался послеоперационный период, который протекает без осложнений.

\section{Клинический случай № 2}

Пациентка Т., 9 лет. Родители впервые обратились в праксис по поводу ходьбы девочки на носках. Ребенок от второй беременности, вторых родов. Во время первой беременности у матери наблюдался легкий тромбоз, поэтому в течение второй беременности также вводился гепарин. Роды в 41 нед, без осложнений. На момент рождения вес ребенка - 3450 г, рост - 50 см. Период новорожденности протекал без особенностей. Впервые пошла девочка в возрасте 12 мес. С 3 лет возникла ходьба на носках, которая проявлялась в $80 \%$ от всего времени ходьбы.

Родители пациентки не являются кровными родственниками.

С 2 лет у ребенка отмечается ночной диурез. Жалобы на боли отсутствуют, однако отмечается быстрая утомляемость при ходьбе. Задержки развития не отмечено, соматической патологии не выявлено.

Генетическая причина ходьбы была заподозрена после осмотра ортопедом, педиатром, хирургом и неврологом и 24 сеансов физиотерапии, которые не привели к положительному результату. На обеих ногах выявлена заостренная пятка (pes cavus) и широкая передняя часть стопы, а также положительный V-знак над ахилловым сухожилием. Аномалий верхних конечностей не отмечено.

В поясничном отделе позвоночника обнаружен гиперлордоз $40^{\circ}$.

Девочка могла удерживать позу в положении на одной ноге в течение 1 секунды с обеих сторон.

В тесте на подвижность голеностопного сустава с помощью нейтрально-нулевого метода диапазон движений составил
0-0-50 вправо и влево при тыльном сгибании и 5-0-50 влево и вправо - при подошвенном. Других отклонений не было.

Генетическое тестирование обнаружило мутацию в гене NDRG1 с гетерозиготным вариантом $c .1053 \_1082 \mathrm{del}$ и $N M \_001135242.1$ p.Thr360_Gly369del. Частота минорного аллеля составила $0,13 \%$.

Прогноз in silico был патогенным, мутация наследуется как аутосомно-рецессивный признак.

Пациентка успешно прошла терапию с применением пирамидальных стелек и ночных ортезов для иммобилизации. Через 8 недель лечения частота ходьбы на носках составила $20 \%$ от всего времени ходьбы.

\section{Обсуждение}

Функция гена $N D R G 1$ описана как имеющая отношение к росту, хотя он может функционировать как сигнальный белок при разделении клеток и играть роль в периферической нервной системе [4]. Известна связь гена NDRG1 с наследственной сенсомоторной нейропатией - болезнью Шарко-МариТута типа 4D [5]. Заболевание характеризуется мышечной слабостью, атрофией, двигательными и сенсорными нарушениями, деформацией стопы и широко распространенным развитием глухоты на третьем десятилетии жизни [6]. Симптомы в виде нарушения походки появляются в первом десятилетии жизни и усугубляются деформациями скелета стоп, при этом начало бега часто откладывается [7, 8]. Кроме того, Y. Okamoto и соавт. (2014) описали при данной патологии задержку двигательных навыков, нестабильную походку, а также pes cavus, молоткообразные пальцы стопы и когтистые кисти [9].

Отметим, что у обеих пациенток отсутствовала неврологическая симптоматика, ассоциированная с болезнью ШаркоМари-Тута, в то же время диагноз ИХН также сомнителен, поскольку в обоих клинических случаях потребовалось достаточно серьезное лечение. Поэтому разумно предположить, что обе пациентки ходят на цыпочках по генетической причине.

\section{Заключение}

Таким образом, в данной статье у двух пациенток впервые описана связь между выраженной ходьбой на носках и мутацией в гене $N D R G 1$ без установленной болезни Шарко-Мари-Тута.

КОНФАИКТ ИНТЕРЕСОВ. Г-н Помарино яВАяется влаАельцем праксиса по лечению аномалий походки и разработчиком метода лечения ИХН. CONFLICT OF INTERESTS. Mr. Pomarino is the owner of gait abnormalities praxis and developer of method idiopathic toe walking.

\section{Митература/References}

1. Ruzbarsky J. J., Scher D., Dodwell E. Toe walking: causes, epidemiology, assessment, and treatment // Curr Opin Pediatr. 2016; 28 (1): 40-46. DOI: 10.1097/ MOP.0000000000000302.

2. Pomarino D., Ramírez Lamas J., Martin S., Pomarino A. Literature Review of Idiopathic Toe Walking: Etiology, Prevalence, Classification, and Treatment // Foot Ankle Spec. 2017; 10 (4): 337-342. DOI: 10.1177/1938640016687370.

3. Pomarino D., Thren A., Morigeau S., Thren J. The Genetic Causes of Toe Walking in Children // Genetics and Molecular Biology Research. 2018; 2 (9): 1-5.

4. Kalaydjieva L., Gresham D., Gooding R., Heather L., Baas F., de Jonge R., Blechschmidt K., Angelicheva D., Chandler D., Worsley P., Rosenthal A., King R. H., Thomas $P$. $K$. N-myc downstream-regulated gene 1 is mutated in hereditary motor and sensory neuropathy-Lom // Am J Hum Genet. 2000; 67 (1): 47-58. DOI: $10.1086 / 302978$.

5. NLM, 2019. Clinvar. [Online] Available at: https://www.ncbi.nlm.nih.gov/clinvar/variation/639524/ [Accessed 28 June 2020].

Полный список литературы смотрите на нашем сайте https://www.lvrach.ru/ 